

\title{
Editorial
}

\section{Internationalising paramedic education through clinical}

\section{placement experiences}

\author{
Gavin Smith BParaStudies, GradDipEmergHlth, MEH, PhD ${ }^{1}$
}

\begin{abstract}
Affiliation:
${ }^{1}$ Victoria University Centre for Chronic Disease Prevention and Management, College of Health and Biomedicine, Melbourne, Victoria
\end{abstract}

Paramedic education has undergone significant change since the closing years of the twentieth century. The move from vocational to higher educational sector has created opportunities for paramedic students and the industry in general to conceptualise a definition of the modern paramedic from an educational perspective. One of the more interesting facets of change has been the 'globalisation' of paramedic students, with an increasing number seeking employment at the completion of their degree outside of the state, or country, where they gained their degree. Australian paramedic graduates are well regarded with respect to employability, and those attending the 2014 Paramedics Australasia conference would have noted substantive recruitment campaigns by international providers, including the United Kingdom and United Arab Emirates. This is reflective, and a timely reminder of, the growing regard for Australian paramedics across the world.

A feature of paramedic undergraduate education is the opportunity to engage in clinical placement to enhance the integration of theoretical and practical learning in a real-world environment. In Victoria this has traditionally involved a relationship between the university and the state service provider, Ambulance Victoria. However, the high number of student paramedics generated within Victoria has created challenges for the universities in fulfilling course requirements, the students in achieving this valuable experience, and the service provider in the logistical provision of such placements. Increasingly, universities are looking to provide quality alternative clinical placements where paramedic students can immerse themselves in real-world learning with an international flavour (1-3).

At Victoria University in 2014, two international clinical placement opportunities were offered, albeit to a limited number of students following a competitive selection process. The first, to the United Kingdom, provided students the opportunity to engage in clinical observation shifts with paramedics in a similar system to that used in Victoria. The second was a somewhat ambitious inaugural tour to Israel, with clinical placements hosted by Magen David Adom (MDA), the national ambulance service provider. The Israeli emergency medical services system is similar to that of Victoria, with a two-tiered model of service provision, and obvious ties to its origins in the American model.

On the Israeli tour 15 students engaged in 11 clinical placement shifts of 8 hours duration (plus incidental overtime) in the cities of Tel Aviv and Jerusalem. These shifts were rostered across a 24-hour cycle, so the students were able to experience the rigours of shift work as well as time of day factors affecting workload. Some 370 cases were attended during this period, with a similar casemix to that of Victoria including 23 cardiac arrests. One feature of this tour and its timing (during the mid-semester break), was an unforseen heightening of regional tensions that resulted in the group finding itself in close proximity to military activity.

One outstanding feature of the tour experience was the overriding similarity of paramedics globally. It seems that the same issues of funding, patient needs, hospital overcrowding, and the inevitability of societal demands on resources permeate every corner of the paramedic world. Somehow the paramedic topics of conversation from metropolitan Melbourne had filtered through the ether and echoed through the West Bank and downtown Tel Aviv. There was an obvious disparity between the reality of working with MDA on the ground and that being broadcast in the international media. The hosts at MDA were a mix of Jewish and Muslim Israelis whose professionalism knew no boundaries, whose focus was at all times patient care regardless of race or religion, and who tried to explain the complexity of the region in an objective and understandable manner to the tour group. The students on tour were also fortunate to have experienced both sides of the complex regional political argument at different times during the tour. From the elderly Jewish lady who provided a tirade as she shared a stairwell during an air raid, and subsequently from a Palestinian stall holder in Old Jerusalem who drew a student and the tour group leader into his store before delivering a clandestine spiel that seemed to last longer than the t-shirt purchased by the student. The tour group were grateful for both of their opinions, capable of listening objectively to opposing views, and far from qualified to draw any conclusions or to take a political stance. 
The benefits for paramedic students participating in international study tours are multi-faceted; and include the development of strong teamwork skills, the ability to demonstrate independence and responsibility, understanding of the nature of paramedic clinical practice, understanding and appreciating cultural diversity, and the ability to connect and develop lasting international professional networks and friendships while representing their university and their country $(2,3)$. The value of conducting international study tour programs, with a view to providing paramedic graduates with unique development opportunities, cannot be viewed simply through postgraduate employment rates at the local and international level, but rather should be contextualised in a more meaningful and often less quantifiable manner (2-5). The impact of this tour on one of the students in particular highlights this point. Having never travelled outside Australia, this student managed to get separated and lost on day one in the Grand Bazaar (a vast maze of small alleys and stalls) in Istanbul, where the tour group spent 2 days before entering Israel. This could have been an overwhelming and disastrous start to her tour, but she retained the presence of mind to find the hotel and was soon reunited with the group. In Israel she attended a particularly challenging critical incident case involving severe burns to an entire Palestinian family, and following active participation in the resuscitation of a paediatric cardiac arrest consequent of the burns, was taken aside and introduced to the Prime Minister of Israel, Benjamin Netanyahu, who thanked her personally for travelling to work with MDA on this occasion. It would be impossible to plan such an experience for any paramedic student, and yet the incidental value for personal development, expressed afterwards by this student, is immeasurable. This student has recently accepted an offer of employment from St John Ambulance, the service provider in the Northern Territory.

It can be said that the development of student paramedics is enhanced through participation in international study tours and clinical placements. The integration of these activities into university undergraduate programs is invaluable in providing employers globally with prospective employees who have a solid foundation in learning enhanced by practical application in an international setting. The continued evolution and refinement of these programs will also add value to the development of the professional paramedic, especially with future submissions to this journal that provide a measure of international clinical placement effectiveness through personal experience and research.

\section{A/Prof Gavin Smith}

Associate Editor

Australasian Journal of Paramedicine

\section{References}

1. Burgess CA, Reimer-Kirkham S, Astle B. Motivation and international clinical placements: shifting nursing students to a global citizenship perspective. Int J Nurs Educ Scholarsh 2014;11(1):75-82.

2. Edgecomb K, Jennings M, Bowden M. International nursing students and what impacts their clinical learning: literature review. Nurse Educ Today 2013;33:138-42.

3. Sloand E, Bower K, Groves S. Challenges and benefits of international clinical placements in public health nursing. Nurse Educ 2008;33(1):35-8.

4. Grant E, McKenna L. International clinical placements for undergraduate students. J Clin Nurs 2003;12:529-35.

5. Racine L, Perron A. Unmasking the predicament of cultural voyeurism: a postcolonial analysis of international nursing placements. Nursing Enquiry 2012;19:190-201. 